\title{
Cannabinoid receptor type-2 stimulation, blockade, and deletion alter the vascular inflammatory responses to traumatic brain injury
}

Peter S Amenta ${ }^{1}$, Jack I Jallo ${ }^{1}$, Ronald F Tuma ${ }^{3}$, D. Craig Hooper ${ }^{2}$ and Melanie B Elliott ${ }^{1 *}$

\begin{abstract}
Background: Immunomodulatory therapies have been identified as interventions for secondary injury after traumatic brain injury $(\mathrm{TBI})$. The cannabinoid receptor type-2 $\left(\mathrm{CB}_{2} \mathrm{R}\right)$ is proposed to play an important, endogenous role in regulating inflammation. The effects of $\mathrm{CB}_{2} \mathrm{R}$ stimulation, blockade, and deletion on the neurovascular inflammatory responses to TBI were assessed.

Methods: Wild-type C57BL/6 or CB 2 R knockout mice were randomly assigned to controlled cortical impact (CCl) injury or to craniotomy control groups. The effects of treatment with synthetic, selective $\mathrm{CB}_{2} \mathrm{R}$ agonists (0-1966 and JWH-133), a selective $\mathrm{CB}_{2} \mathrm{R}$ antagonist, or vehicle solution administered to $\mathrm{CCl}$ groups were assessed at 1-day after injury. Changes in TNF-a, intracellular adhesion molecule (ICAM-1), inducible nitric oxide synthase (iNOS), macrophage/microglial ionized calcium-binding adaptor molecule, and blood-brain-barrier (BBB) permeability were assessed using ELISA, quantitative RT-PCR, immunohistochemistry, and fluorometric analysis of sodium fluorescein uptake. $\mathrm{CB}_{2} \mathrm{R}$ knockouts and wild-type mice with $\mathrm{CCl}$ injury were treated with a $\mathrm{CB}_{2} \mathrm{R}$ agonist or vehicle treatment.

Results: TNF-a mRNA increased at 6 hours and 1 to 3 days after $\mathrm{CCl}_{1}$ a $\mathrm{CB}_{2} \mathrm{R}$ antagonist and genetic knockout of the $\mathrm{CB}_{2} \mathrm{R}$ exacerbated TNF-a mRNA expression. Treatment with a $\mathrm{CB}_{2} \mathrm{R}$ agonist attenuated TNF-a protein levels indicating post-transcriptional mechanisms. Intracellular adhesion molecule (ICAM-1) mRNA was increased at 6 hours, and at 1 to 2 days after $\mathrm{CCl}$, reduced in mice treated with a $\mathrm{CB}_{2} \mathrm{R}$ agonist, and increased in $\mathrm{CB}_{2} \mathrm{R}$ knockout mice with $\mathrm{CCl}$. Sodium fluorescein uptake was increased in $\mathrm{CB}_{2} \mathrm{R}$ knockouts after $\mathrm{CCl}$, with and without a $\mathrm{CB}_{2} \mathrm{R}$ agonist. iNOS mRNA expression peaked early (6 hours) and remained increased from 1 to 3 days after injury. Treatment with a $\mathrm{CB}_{2} \mathrm{R}$ agonist attenuated increases in iNOS mRNA expression, while genetic deletion of the $\mathrm{CB}_{2} \mathrm{R}$ resulted in substantial increases in iNOS expression. Double label immunohistochemistry confirmed that iNOS was expressed by macrophage/microglia in the injured cortex.
\end{abstract}

Conclusion: Findings demonstrate that the endogenous cannabinoid system and $\mathrm{CB}_{2} \mathrm{R}$ play an important role in regulating inflammation and neurovascular responses in the traumatically injured brain. $\mathrm{CB}_{2} \mathrm{R}$ stimulation with two agonists (0-1966 and JWH-133) dampened post-traumatic inflammation, while blockade or deletion of the $\mathrm{CB}_{2} \mathrm{R}$ worsened inflammation. Findings support previous evidence that modulating the $\mathrm{CB}_{2} \mathrm{R}$ alters infiltrating macrophages and activated resident microglia. Further investigation into the role of the $C_{2} R$ on specific immune cell populations in the injured brain is warranted.

Keywords: Controlled cortical impact, Traumatic brain injury, Cannabinoid, Inflammation, Intracellular adhesion molecule

\footnotetext{
* Correspondence: Melanie.elliott@jefferson.edu

'Department of Neurological Surgery, Thomas Jefferson University Hospital,

1020 Locust Street, Thomas Jefferson University, Philadelphia, PA 19107, USA

Full list of author information is available at the end of the article
} 


\section{Introduction}

Traumatic brain injury (TBI) affects over 1.4 million Americans annually, with many suffering fatal or permanently disabling injuries $[1,2]$. Blood-brain-barrier (BBB) disruption, a result of the post-traumatic inflammatory response, is a proposed mechanism of secondary injury and contributes to cell death or dysfunction, worsening neurologic function, and ultimately, to poorer clinical outcome $[3,4]$. It is also well-recognized, however, that this same inflammatory response plays an important role in the processes necessary for repair and recovery [5]. The initial traumatic insult induces the release of pro-inflammatory cytokines and chemokines triggering endothelial cell activation, chemoattractant signaling, and immune cell infiltration [6]. The release of TNF- $\alpha$ up-regulates the expression of intracellular adhesion molecule-1 (ICAM-1), which promotes the adherence of immune cells to the endothelium and subsequent transmigration to sites of inflammation [7]. The result of an inflammatory-driven barrier breakdown is an enhancement of a cytotoxic environment in the setting of already compromised neurons [8-10]. Infiltrating immune cells and resident microglia have been shown to demonstrate opposing pro- and antiinflammatory phenotypes [11,12]. Pro-inflammatory cell phenotypes release cytokines and express enzymes such as inducible nitric oxide synthase (iNOS) that generate damaging free radicals and further disrupt BBB function. Anti-inflammatory phenotypes produce cytokines and growth factors that down-regulate free radical generating pathways, which can promote healing and regeneration. Optimal modulation of the post-traumatic inflammatory response will limit damage and promote reparative interactions between the immune and nervous systems.

A number of cellular targets have been identified as potential therapeutic interventions for the post-traumatic inflammatory response. The endocannabinoid system, as documented previously, represents a specialized group of endogenous neurotransmitters with a broad range of function [13]. In particular, the cannabinoid receptor type-2 $\left(\mathrm{CB}_{2} \mathrm{R}\right)$, expressed predominantly by circulating immune cells and resident microglia, plays an important role in the immune response to injury. Upon stimulation with its ligand, the $\mathrm{CB}_{2} \mathrm{R}$ possesses potent immunomodulatory and anti-inflammatory properties as reviewed by Cabral et al. [14-18]. In a series of studies, stimulation of the $\mathrm{CB}_{2} \mathrm{R}$ has been shown to dampen post-TBI inflammation including infiltrating/resident immune cell activation and neurovascular disruption, all of which were accompanied by improved functional outcome following TBI and spinal cord injuries [19-23]. These findings are supported by other laboratories, showing treatment with a $\mathrm{CB}_{2} \mathrm{R}$ agonist results in immunomodulation and neuroprotection in models of brain injury and neurodegeneration $[18,24]$.
Acute immunomodulation through $\mathrm{CB}_{2} \mathrm{R}$ ligands is associated with improvements in outcome in animal models of brain and spinal cord injury, Huntington's disease, and Parkinson's disease [18-20,22-25]. Emerging evidence points to the modulation of microglia and infiltrating macrophages as a key component in $\mathrm{CB}_{2} \mathrm{R}$-mediated improvements in functional outcome. Furthermore, these same immunomodulatory processes have also been implicated as important moderators underlying the histopathologic changes observed in cases of improved outcome following injury [18,19,22-24,26,27]. Microglial activation and inflammation in the traumatized brain can persist for years after TBI $[28,29]$, and like macrophages, express pro-inflammatory (M1) and anti-inflammatory (M2) phenotypes $[11,12,30]$. A 'loss of function' in the M2 cell phenotype may underlie chronic inflammation such as occurs with traumatic brain injury [11]. Promoting the healing function of $\mathrm{M} 2$ immune cells through $\mathrm{CB}_{2}$ receptor stimulation may inhibit the detrimental effects of long-term inflammation including synapse loss, neuronal degeneration, and cognitive function [11]. The present study further investigates the role of the $\mathrm{CB}_{2} \mathrm{R}$ in regulating acute inflammatory vascular responses to TBI using $\mathrm{CB}_{2}$ receptor stimulation, blockade and deletion. We also report the evidence linking $\mathrm{CB}_{2} \mathrm{R}$ stimulation and alteration of the inflammatory cell phenotype.

\section{Methods}

\section{Animal care and housing}

Prior to initiating any research, the Thomas Jefferson University Institutional Animal Care and Use Committee (IACUC) reviewed and approved the research protocol and the use of male C57BL/6 mice. Animal care and use was monitored by the University Animal Care and Use Committee to assure compliance with the provisions of Federal Regulations and the NIH 'Guide for the Care and Use of Laboratory Animals'. All mice were housed in the Thomas Jefferson University Laboratory Animal Services Facility which is accredited by the American Association for the Accreditation of Laboratory Animal Care and complies with NIH standards.

\section{Experimental design}

Seventy-four ( $\mathrm{n}=74$ ) adult male mice at approximately 8 weeks of age (weighing 22 to $24 \mathrm{~g}$ ), including strains of C57BL/6 wild-type mice (Charles River, Wilmington, MA, USA) or $\mathrm{CB}_{2} \mathrm{R}$ knockout B6.129P2-Cnr2 $2^{\text {tm } 1 \text { Dgen }} / \mathrm{J}$ mice (Taconic, Hudson, NY, USA) were randomly assigned to undergo controlled cortical impact injury $(\mathrm{n}=66)$ or serve as craniotomy controls (control) $(\mathrm{n}=8)$. There were three study arms to determine the effects of $\mathrm{CB}_{2} \mathrm{R}$ modulation on genes and proteins expression for primary vascular inflammatory markers (TNF- $\alpha$, ICAM, iNOS, and BBB permeability) which included: (1) CCI injury over time 
compared to craniotomy, (2) $\mathrm{CB}_{2} \mathrm{R}$ agonists and $\mathrm{CB}_{2} \mathrm{R}$ antagonist compared to vehicle-treated mice, and (3) $\mathrm{CB}_{2} \mathrm{R}$ knockout $\left(\mathrm{CB}_{2} \mathrm{R} \mathrm{KO}\right) \mathrm{CCI}$ groups with and without JWH133 compared to wild-type CCI (Figure 1). Endpoints for CCI time course experiments were at either 6 hours $(n=4)$ or $1(n=10), 2(n=7)$, or $3(n=5)$ days after CCI injury. Two administrations of synthetic selective $\mathrm{CB}_{2} \mathrm{R}$ agonists, 0-1966 ( $\mathrm{n}=8)$ or JWH-133 ( $\mathrm{n}=12)$, a selective $\mathrm{CB}_{2} \mathrm{R}$ antagonist, SR144528 $(n=4)$, or vehicle solution $(n=10)$ were administered to wild-type CCI mice as described below. To determine the selectivity for the $\mathrm{CB}_{2} \mathrm{R}$, knockout mice lacking the $\mathrm{CB}_{2} \mathrm{R}$ were treated with a $\mathrm{CB}_{2} \mathrm{R}$ agonist JWH-133 (n=3) and 0-1966 ( $\mathrm{n}=4)$ or vehicle $(\mathrm{n}=9)$ and compared to wild-type CCI mice $(\mathrm{n}=8)$. Controls underwent all surgical procedures including an equal time of isoflurane exposure, buprenorphine injection, incision and craniotomy but were not subjected to $\mathrm{CCI}$ injury, did not receive treatment or vehicle, and were euthanized at 3 days post-operatively. All surgeries and experimental post-mortem procedures were performed so that, within each cohort of mice, craniotomy or vehicletreated control groups were run in parallel with their respective experimental groups to insure consistent environmental conditions. On an annual basis, there is a 6 to $8 \%$ mortality rate for our CCI injury model due to the formation of fatal hematomas or cerebrovascular blood clots. Controlled cortical impact injury (CCI) injury resulted in a loss of 6 of the original 66experimental CCI mice (9\% mortality rate) equally distributed among groups, and final group sizes were reported for each experimental outcome (see figures).

\section{Traumatic brain injury}

Traumatic brain injury was induced using CCI injury, a highly reproducible non-penetrating brain injury model [31]. Mice were injured using methods previously described by our laboratory $[19,23,32]$. Anesthesia was induced with $3 \%$ isoflurane and maintained throughout the procedure at a dose of $2.5 \%$ isoflurane. Prior to the start of the procedure, all mice were injected with shortacting buprenorphine (0.01 cc subcutaneous) for acute post-operative pain control. A right-sided $4 \mathrm{~mm}$ craniotomy was performed at $1 \mathrm{~mm}$ posterior to bregma exposing the mouse somatosensory cortex. A rounded aluminum $3 \mathrm{~mm}$ diameter stereotaxic impactor tip (MyNeuroLab, St. Louis, MO, USA) was used to produce a cortical injury at a $1.0 \mathrm{~mm}$ depth, $3 \mathrm{~m} / \mathrm{s}$ velocity, and $100 \mathrm{msec}$ contact time. Following injury, the bone flap was sealed with permanent cyanoacrylate-based fast-acting adhesive closures and the skin was closed with 6.0 silk sutures. Postoperative care included warming with indirect heat from a heat lamp until ambulation resumed, and unlimited access to food and water. Brain and core body temperature were maintained at $37 \pm 0.5^{\circ} \mathrm{C}$ throughout the procedure and monitored with temporalis muscle and rectal temperature probes to avoid the neuroprotective effects of anesthesiainduced hypothermia.

\section{Treatment administration}

Stimulation of the $\mathrm{CB}_{2}$ receptor was performed using agonists 0-1966 (Organix Inc., Woburn, MA, USA) or JWH-133 (Tocris Bioscience, Minneapolis, MN, USA). 0-1966 was used for the TNF and ICAM PCR experiments, while

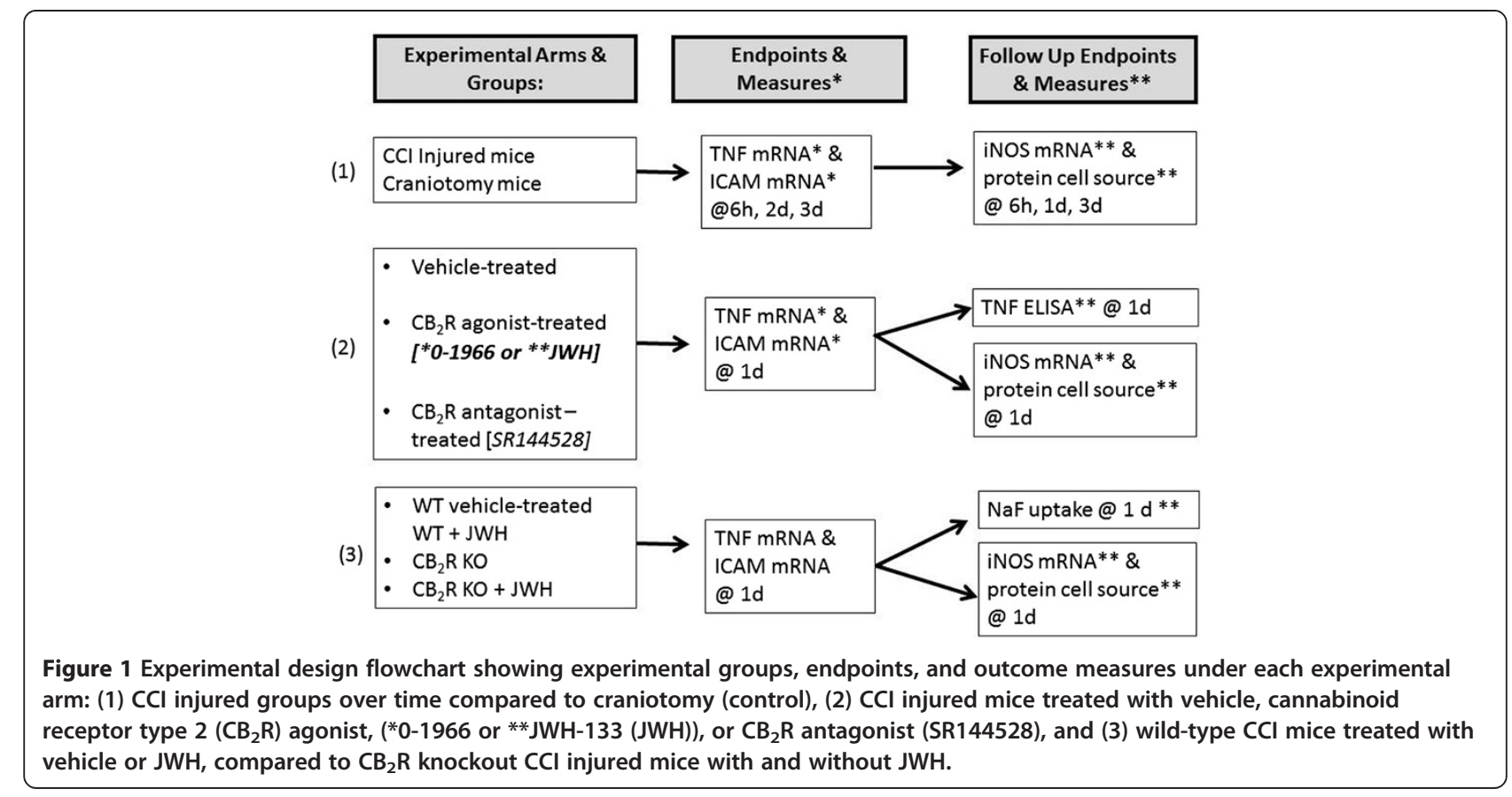


JWH-133 was used in all other experiments (Figure 1). The $\mathrm{CB}_{2} \mathrm{R}$ agonist was switched to JWH-133 in the later experiments in this study because it had the same selectivity profile for $\mathrm{CB}_{2} \mathrm{R}$ as $0-1966$ but with better solubility, was easier to administer, and was commercially available as a solution. 0-1966 was dissolved in a pure ethanol:emulphor:normal saline solution (1:1:18) resulting in a final concentration of $0.5 \mathrm{mg} / \mathrm{mL}$. The $\mathrm{CB}_{2} \mathrm{R}$ agonist, 0-1966, also known as 0-1966A, is an analog of bicyclic resorcinols (dimethoxy-resorcinol-dimethylheptyl) and structurally similar to cannabidiol as described by Wiley et al. [33]. 0-1966 demonstrates 225-fold higher selectivity for the $\mathrm{CB}_{2} \mathrm{R}(\mathrm{Ki}=23 \pm 2.1 \mathrm{nM})$ compared to $\mathrm{CB}_{1} \mathrm{R}(\mathrm{Ki}=$ $5,055 \pm 984 \mathrm{nM})$ [33]. JWH-133 selective $\mathrm{CB}_{2} \mathrm{R}$ agonist $(\mathrm{Ki}=3.4 \mathrm{nM})$, in water-soluble emulsion Tocrisolve TM 100 (Tocris Catalog Number 1684) has appoximately 200fold selectivity over CB1 receptors. The times for repeated intraperitoneal (ip) injections of 0-1966 (5 mg/ $\mathrm{kg}$ ) and JWH-133 $(1 \mathrm{mg} / \mathrm{kg})$ for the one-day endpoint were at either 2 or 18 hours post-CCI. The timing of treatment administrations were based on our previous studies [19]. Dosages were based both on preliminary dosing studies performed by our laboratory for our TBI model as well as on previous studies on models of stroke and spinal cord injury [19-22,34]. Vehicle solution was prepared in an identical manner to include $0.2 \mathrm{~mL}$ of pure ethanol: emulphor:normal saline solution (1:1:18) minus the cannabinoid and administered at the same time points as 01966. The selective $\mathrm{CB}_{2} \mathrm{R}$ antagonist, SR144528, (Cayman Chemical, Ann Arbor, MI, USA) was dissolved in DMSO: emulphor:normal saline solution $(1: 1: 18)$ and injected at $5 \mathrm{mg} / \mathrm{kg}$ at 2 and 18 hours post-CCI.

\section{BBB assessment}

Fluid-phase BBB permeability was assessed using sodium fluorescein $(\mathrm{NaF})$ at 1 day post-CCI in wild-type, $\mathrm{CB}_{2} \mathrm{R}$ $\mathrm{KO}$ mice with and without a $\mathrm{CB}_{2} \mathrm{R}$ agonist (JWH-133) or controls as previously described by our laboratories [8]. NaF uptake assay was performed for 20 mice randomly divided into CCI subgroups euthanized at either 1 day $(n=236)$ or serving as controls $(n=4)$. CCI subgroups consisted of wild-type treated with vehicle or JWH-133, and $\mathrm{CB}_{2} \mathrm{R}$ KO receiving vehicle or JWH-133. Brain samples were run in duplicate experiments. We selected $\mathrm{NaF}$ to evaluate changes in $\mathrm{BBB}$ permeability due to its low molecular weight (376 Da) compared to others probes that bind to albumin such as Evans Blue, horseradish peroxidase (HRP), or IgG ( $\geq 67,000 \mathrm{Da})$. Thus, $\mathrm{NaF}$ is a more sensitive probe that allows for detection of smaller leaks in the barrier. Mice were injected ip with $100 \mu \mathrm{L}$ of $10 \% \mathrm{NaF}$ in PBS and the $\mathrm{NaF}$ was allowed to circulate for 10 minutes. Following administration of a lethal dose of sodium pentobarbital, cardiac blood was collected followed by transcardial perfusion with $15 \mathrm{~mL}$ of heparin
(1,000 U/L) in PBS. Brains were sectioned into a left and right hemisphere and micro-dissected to separate the cerebral cortex, and processed immediately. To determine BBB permeability, tissues were weighed, homogenized in $1 / 10$ dilution in PBS and centrifuged at $14,000 \times \mathrm{g}$ for 2 minutes. Five-hundred microliters of the clarified supernatant was transferred into $500 \mu \mathrm{L}$ of $15 \%$ trichloroacetic acid and centrifuged at $10,000 \times \mathrm{g}$ for 10 minutes while the pellet was retained for RNA isolation. One hundred and twenty-five microliters of $5 \mathrm{~N} \mathrm{NaOH}$ was added to $500 \mu \mathrm{L}$ of the supernatant, and the amount of fluorescein for each sample was determined using standards ranging from 125 to $4,000 \mu \mathrm{g}$ on a Cytofluor II fluorometer (PerSeptive Biosystems, Framingham, MA, USA). Serum levels of sodium fluorescein were assessed as previously described so that signals in CNS tissue samples could be normalized against the amount present in the circulation. $\mathrm{NaF}$ uptake into each brain region of interest is expressed as (ug/g NaF in cortex)/( $\mu \mathrm{g} \mathrm{NaF}$ in serum).

\section{RT-PCR}

The pellet isolated during the $\mathrm{BBB}$ assessment outlined above was subsequently used for RNA isolation. Total RNA was extracted with the RNeasy Miniprep Kit (Qiagen, Valencia, CA, USA), reverse transcribed into cDNA with MMLV reverse transcriptase (Promega, Madison, WI, USA) and then measured by quantitative real-time PCR with gene-specific primers and probes [35]. IQ supermix and the iCycler iQ real-time detection system were also used for quantification (Bio-Rad Laboratories, Hercules, CA, USA). All samples were run in duplicate and compared to cDNA gene standards to determine copy numbers, which were normalized to the copy number of each sample's housekeeping gene L13. Levels of mRNA are reported as the fold change in gene expression of normalized to the endogenous reference gene L13 and relative to the untreated, craniotomy controls.

\section{Immunohistochemistry}

Mice were administered a lethal dose of sodium pentobarbital (120 mg/kg, ip) and underwent cardiac perfusion with heparinized saline followed by $4 \%$ paraformaldehyde. Brains were post-fixed in $4 \%$ paraformaldehyde for 24 hours, then transferred to $30 \%$ sucrose for storage. Frozen sections were cut coronally with a cryostat at $-24^{\circ} \mathrm{C}$ (20 $\mu \mathrm{m}$ thick), and air dried overnight. Tissues were incubated in 10\% NGS in 0.3\% Triton-100. Coronal brain sections were labeled using the following primary antibodies overnight at room temperature: (1) rabbit antimouse iNOS (1:200; Enzo Life Science, Farmingdale, NY, USA) and (2) rabbit anti-mouse ionized calcium-binding adaptor molecule-1 (Iba-1) (1:250; Wako Pure Chemical Industries, Richmond, VA, USA). Fluorescent secondary antibodies DyLight 488- or 549-conjugated AffiniPure 
Goat anti-rabbit IgG (Jackson ImmunoResearch, West Grove, PA, USA) were applied for 2 hours at room temperature. Negative control staining was performed by omitting the primary antibodies.

\section{Statistical analyses}

All statistical analyses were performed using the GraphPad Prism 5 software program (La Jolla, CA, USA). To determine differences between CCI injury and controls at 6 hour, 2 day and 3 day time points, differences between wild-type and knockout mice, and and differences between vehicletreated, agonist-treated, and antagonist-treated groups, statistical comparisons were performed using a one-way ANOVA followed by Bonferroni post hoc analysis for experimental groups compared to control. Significance levels were set at $P<0.05$ for all statistical analyses and results are reported as the mean and SEM.

\section{Results}

TNF-a

The expression of mRNA specific for the pro-inflammatory cytokine TNF- $\alpha$ was significantly increased by comparison with controls at each time points examined after CCI in wild-type mice including 6 hours $(P<0.05), 1$ day $(P<0.001), 2$ and 3 days $(P<0.001)$ (Figure $2 \mathrm{~A}$ and $2 \mathrm{C})$.
Treatment with a $\mathrm{CB}_{2} \mathrm{R}$ antagonist, SR144528, significantly increased TNF- $\alpha$ mRNA expression at 1 day postCCI (ANOVA $P<0.0001, \mathrm{~F}=23.00$ ), but mRNA levels where not altered after administration of a $\mathrm{CB}_{2} \mathrm{R}$ agonist, $0-1966$ (Figure 2B). The increase in TNF- $\alpha$ mRNA mediated by the antagonist are paralleled by genetic deletion of the $\mathrm{CB}_{2} \mathrm{R}$ at one day post-CCI compared to control $(P<$ 0.001 ) and wild-type mice, $P<0.01$ (Figure $2 \mathrm{C}$ ). As shown in Figure 2D, the elevation in the levels of TNF- $\alpha$ protein at 1 day following $\mathrm{CCI}$ were reduced by $\mathrm{CB}_{2} \mathrm{R}$ agonist treatment (Figure 2D).

\section{ICAM}

Increases in intracellular adhesion molecule-1 (ICAM-1) induced by increases in TNF- $\alpha$ were expected to occur in the first few days after injury when macrophage and microglial infiltration to the injured site peaks. ICAM mRNA was found to be significantly increased in the injured cortex at 6 hours, 1 and 2 days compared to controls ANOVA $P<0.05$ (Figure 3A and 3C). ICAM mRNA expression returned to control levels by 3 days after injury. Administration of a 0-1966 significantly reduced ICAM-1 mRNA at one day post-CCI (ANOVA $P<0.01$ and $\mathrm{F}=$ 9.53), while treatment with a $\mathrm{CB}_{2} \mathrm{R}$ antagonist, SR144528, did not change mRNA levels (Figure $3 \mathrm{~B}$ ). CCI induction
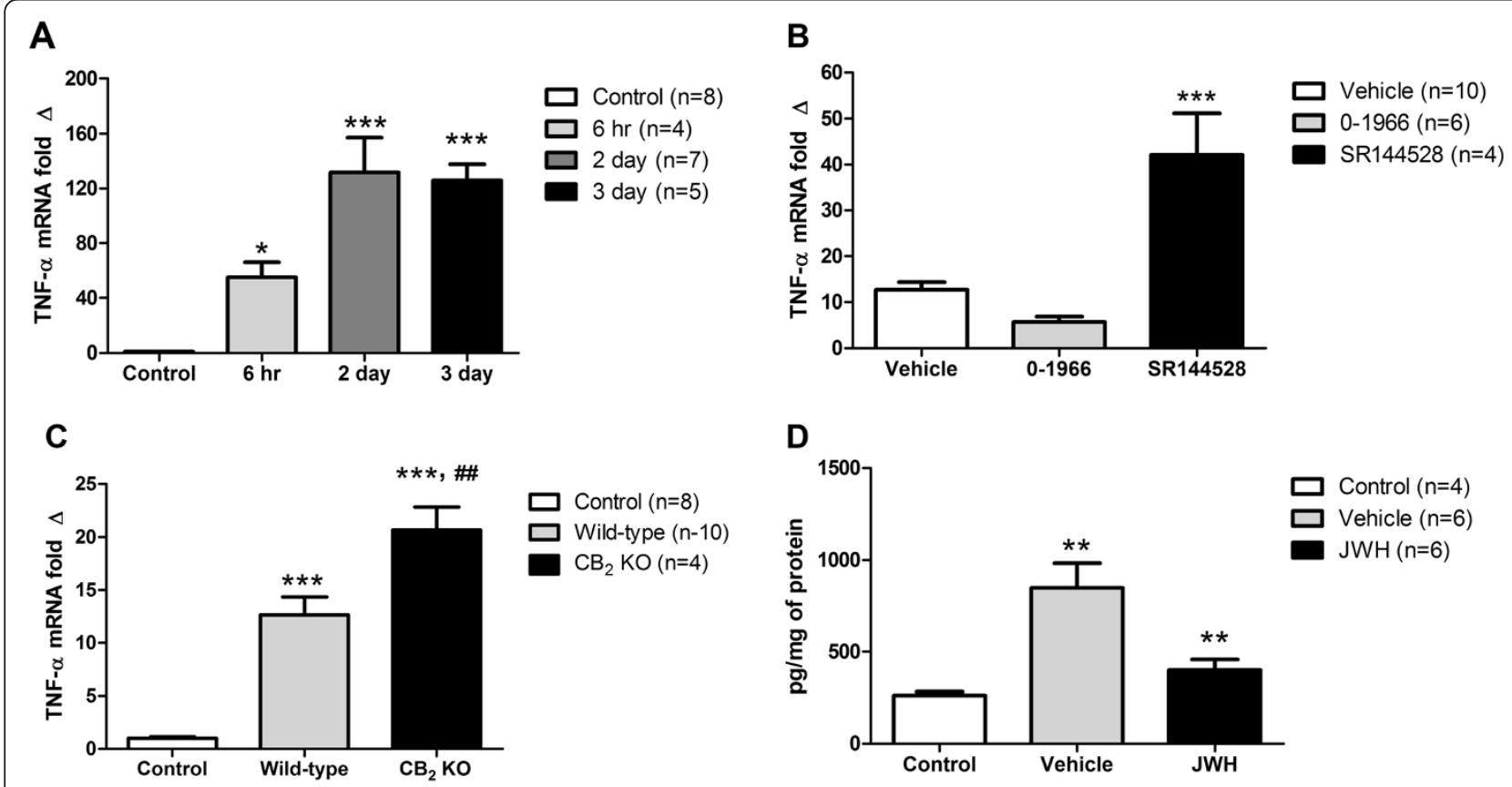

Figure 2 TNF-a mRNA in the injured cortex measured using quantitative real-time PCR (A-C) and TNF-a protein concentration using an enzyme-linked immunosorbent assay (D). (A) TNF-a mRNA at 6 hours, 2 and 3 days after CCl injury compared to craniotomy (control), ${ }^{*} P<0.05$ and ${ }^{* *} P<0.001$. (B) TNF-a mRNA at 1 day after $C C l$ injury in wild-type mice treated with a vehicle solution (vehicle), cannabinoid receptor type-2 $\left(\mathrm{CB}_{2}\right)$ agonist (0-1966) or $\mathrm{CB}_{2}$ receptor antagonist (SR144528) compared to vehicle control, ${ }^{* * *} P<0.001$. (C) TNF-a mRNA at 1 day after $\mathrm{CCl}$ injury in $\mathrm{CB}_{2}$ knockout $\left(\mathrm{CB}_{2} \mathrm{KO}\right)$ and wild-type mice compared to control, ${ }^{* *} P<0.001$, and \#\#P<0.01 compared to wild-type mice. (D) TNF-a protein concentration at 1 day post-CCl in vehicle-treated and $\mathrm{CB}_{2}$ agonist-treated (JWH-133) mice compared to control and vehicle, respectively, ${ }^{* *} P<0.01$. 


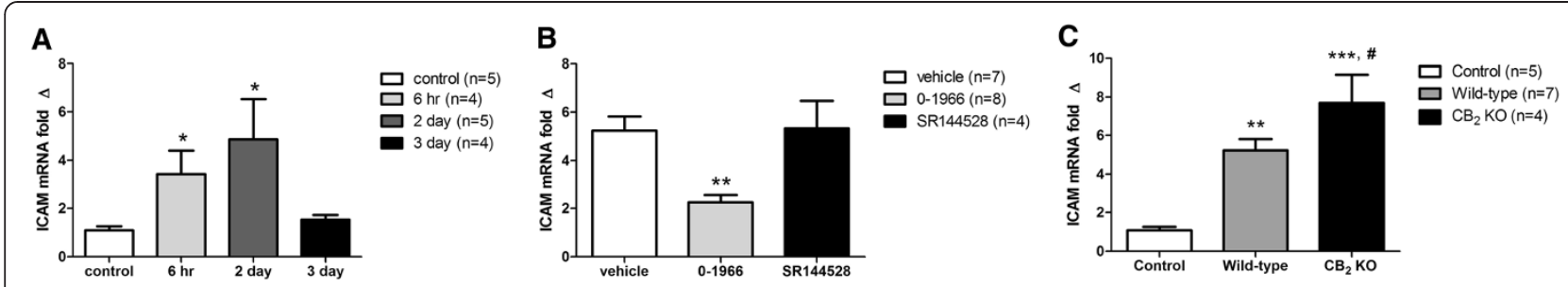

Figure 3 Intracellular adhesion molecule (ICAM) mRNA expression in the injured cortex measured using quantitative real-time PCR. (A) ICAM mRNA at 6 hours, 2 and 3 days after CCl injury compared to control, ${ }^{*} P<0.05$. (B) ICAM mRNA at 1 day after CCI injury in wild-type mice treated with a cannabinoid type-2 $\left(\mathrm{CB}_{2}\right)$ agonist (0-1966) and $\mathrm{CB}_{2}$ antagonist (SR144528) compared to vehicle-treated $C \mathrm{Cl}$ controls, $* * P<0.01$. (C) ICAM mRNA at 1 day after $\mathrm{CCl}$ injury in $\mathrm{CB}_{2}$ knockout $\left(\mathrm{CB}_{2}-/-\right)$ mice and wild-type mice compared to control, ** $P<0.01$ and ${ }^{* * *} P<0.001$; ICAM mRNA post- $C C \mathrm{in} \mathrm{CB}_{2}$ knockout $\left(\mathrm{CB}_{2}-/-\right)$ mice compared to wild-type mice, \#P<0.05.

in genetically modified mice lacking the $\mathrm{CB}_{2} \mathrm{R} \mathrm{KO}$ significantly increased ICAM-1 mRNA expression at 1 day postCCI compared to wild-type mice with and without CCI (ANOVA $P<0.001 \mathrm{~F}=16.63$ ) (Figure $3 \mathrm{C}$ ).

\section{BBB permeability}

BBB permeability was assessed by sodium fluorescein $(\mathrm{NaF})$ uptake into the injured cortex (Figure 4). Treatment with JWH-133 reduced the injury-induced increase in NaF uptake, $P<0.05$. NaF uptake was significantly increased in CCI injured $\mathrm{CB}_{2} \mathrm{R}$ KO mice treated with the $\mathrm{CB}_{2} \mathrm{R}$ agonist or vehicle $(P<0.05 ; P<0.01)$ when compared to $\mathrm{CCI}$-injured wild-type mice. The receptor selectivity of the agonist at the $\mathrm{BBB}$ was demonstrated as $\mathrm{CB}_{2} \mathrm{R}$ KO mice treated with $\mathrm{CB}_{2} \mathrm{R}$ agonist, JWH-133, were not different from $\mathrm{CB}_{2} \mathrm{R} \mathrm{KO}$ mice treated with vehicle control.

\section{iNOS}

iNOS mRNA was significantly increased in the injured cortex at 6 hours, 1 day, 2 , and 3 days after injury $(P<$ $0.001 ; \mathrm{F}=10.57$ ) compared to controls (Figure 5A). Increased iNOS mRNA expression in vehicle-treated mice

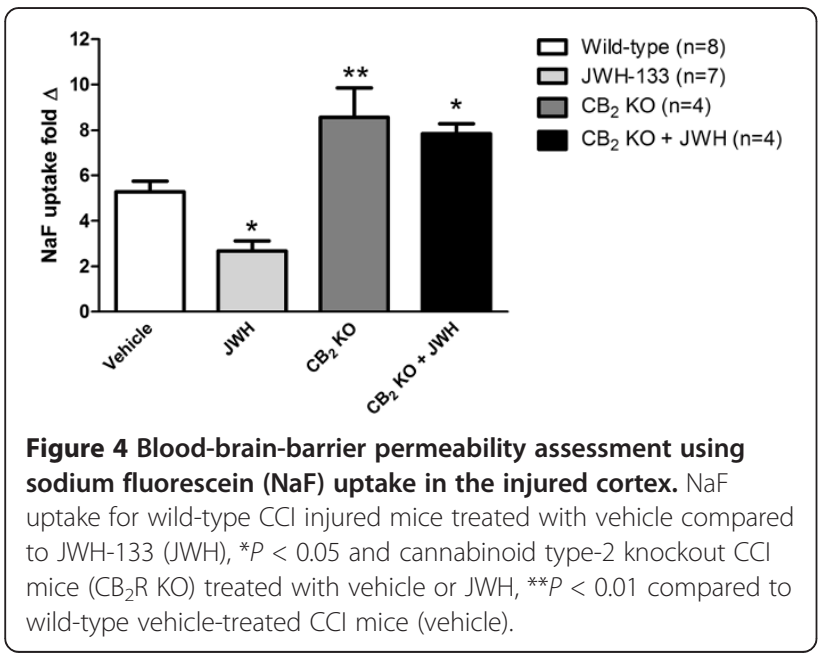

at 1 day post-CCI was attenuated by treatment with a $\mathrm{CB}_{2} \mathrm{R}$ agonist (JWH-133) ANOVA $P<0.001$ and $\mathrm{F}=$ 38.35 (Figure $5 \mathrm{~B}$ ). Interestingly, $\mathrm{CCI}$ injury in knockout mice lacking the $\mathrm{CB}_{2} \mathrm{R}$ resulted in a considerable increase in iNOS mRNA levels (nearly 10-fold increase) in the injured cortex than in CCI injured wild-type mice (ANOVA $P<0.0001$ and $F=20.67$ ). Treatment with agonists JWH-133 and 0-1966 reduced the levels of iNOS in $\mathrm{CB}_{2} \mathrm{R} \mathrm{KO}$ mice indicating mechanisms other than the $\mathrm{CB}_{2} \mathrm{R}$ are involved in the agonist's actions in the injured parenchyma.

Immunohistochemical double labeling for iNOS and a macrophage/microglial specific marker, ionized calciumbinding adaptor molecule (IBA-1) was used to qualitatively evaluate the cellular source of iNOS in the injured cortex (Figure 6). Cells within the cortical tissue surrounding the contusion that were positive for iNOS were co-labeled as macrophage/microglia cells. Some iNOS positive cells were also found distal to the injury in the cingulate cortex and subcortical areas; however, these cells did not co-localize with IBA-1 and showed a neuronal morphology (not shown).

\section{Discussion}

Previously, our laboratory found $\mathrm{CB}_{2} \mathrm{R}$ stimulation reduced $\mathrm{BBB}$ permeability and decreased the number of macrophage/microglia in mice with controlled cortical injury $[19,23]$. We now show that early treatment with a $\mathrm{CB}_{2} \mathrm{R}$ agonist reduces the post-traumatic increase in intracellular adhesion molecule (ICAM-1) mRNA expression after TBI. This effect is accompanied by reduced levels of TNF- $\alpha$ protein. Conversely, genetic deletion of the $C_{2} R$ increased the expression of ICAM- 1 and TNF- $\alpha$ mRNA and exacerbated the BBB permeability that follows TBI. Pharmacological blockade of the $\mathrm{CB}_{2} \mathrm{R}$ with an antagonist also increased the levels of TNF- $\alpha$ mRNA. $C_{2} R$ stimulation improved $\mathrm{BBB}$ integrity after $\mathrm{TBI}$, likely secondary to an attenuation of endothelial cell, macrophage, and microglia activation $[19,23]$. The failure of the $\mathrm{CB}_{2} \mathrm{R}$ agonist to impact these barrier responses in mice lacking the $C_{2} R$ 


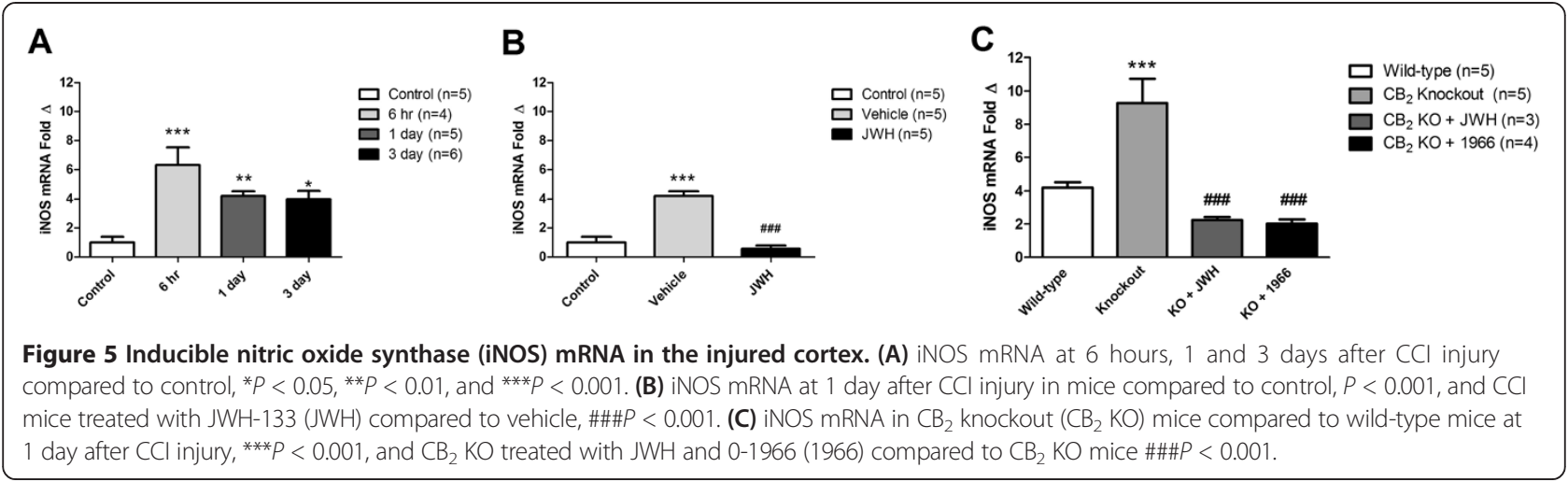

demonstrates that the mechanism of action, at least peripherally or at the blood-brain interface, is selective for the $\mathrm{CB}_{2} \mathrm{R}$. Interesting and not entirely surprising findings were that both $\mathrm{CB}_{2} \mathrm{R}$ agonists in $\mathrm{CB}_{2} \mathrm{R} \mathrm{KO}$ mice showed similar effects in reducing iNOS mRNA after injury. This finding indicates the involvement of a non- $\mathrm{CB}_{2}$ receptor, although due to the low affinity for the $\mathrm{CB}_{1}$ receptor, activation of the $\mathrm{CB}_{1}$ receptor is unlikely to be involved but cannot be completely ruled out. JWH-133 improved cerebral infarction but the effect was absent in $\mathrm{CB}_{2} \mathrm{R} \mathrm{KO}$ mice. [24]. Although there is some overlap between secondary injury mechanisms for stroke and traumatic brain injury, they are in fact distinguishable. $\mathrm{CB}_{2} \mathrm{R}$ selective effects on cell infiltration and $\mathrm{BBB}$ permeability make a different contribution to the damaged brain in stroke compared to TBI. We conclude that the effects of the drug appear to have $\mathrm{CB}_{2} \mathrm{R}$ selectivity peripherally and at the $\mathrm{BBB}$ interface; however, once penetrating the brain, there may be non$\mathrm{CB}_{1}$ and non- $\mathrm{CB}_{2}$ receptors involved. Synthetic $\mathrm{CB} 1 / \mathrm{CB} 2$ receptor ligands can interact with non- $\mathrm{CB}_{1} \mathrm{R}$, non- $\mathrm{CB}_{2} \mathrm{G}$ protein-coupled receptors, transmitter gated channels, ion channels and/or nuclear receptors and is reviewed by Pertwee et al. [36]. While the G protein-coupled receptor GPR55 and potassium channels have been excluded from the actions of JWH-133, others have not yet been elucidated. These findings provide additional support for the concept that the endogenous cannabinoid system facilitates protection against secondary injury following TBI [37,38], and that the neuroprotective effects of $\mathrm{CB}_{2} \mathrm{R}$ stimulation are due, in part, to the modulation of intracranial microvascular function leading to attenuated immune cell infiltration. Similar effects have been reported in studies of ischemic brain injury, whereby reductions in immune cell trafficking accompanied $\mathrm{CB}_{2} \mathrm{R}$ agonist-induced decreases in ICAM-1 expression and BBB damage [20,21,34]. Moreover, following exposure to a variety of inflammatory stimuli, $\mathrm{CB}_{2} \mathrm{R}$ stimulation increased endothelial cell tight junction protein expression in the brain microvasculature and reduced vascular permeability and the expression of ICAM-1 and VCAM-1 [39]. Finally, genetic knockout of the $\mathrm{CB}_{2} \mathrm{R}$ has been shown to worsen inflammation, injury and behavioral deficits in several models of CNS diseases $[18,20,25,39]$. These findings indicate the importance of the $\mathrm{CB}_{2} \mathrm{R}$ in regulating the immune and vascular response, as well as recovery following injury to the brain.

Early, rapid and robust production of pro-inflammatory cytokines, such as TNF- $\alpha$ after TBI, is responsible for the upregulation of ICAM-1 expression and subsequent immune cell infiltration to the injured brain $[7,40]$. TNF- $\alpha$ is a key cytokine that has been implicated in the induction of pathological inflammation in a variety of models including TBI. The finding that TNF- $\alpha$ expression following CCI is strongly elevated by administration of a $\mathrm{CB}_{2}$ antagonist together with its increase in $\mathrm{CB}_{2}$ knockout mice subject to
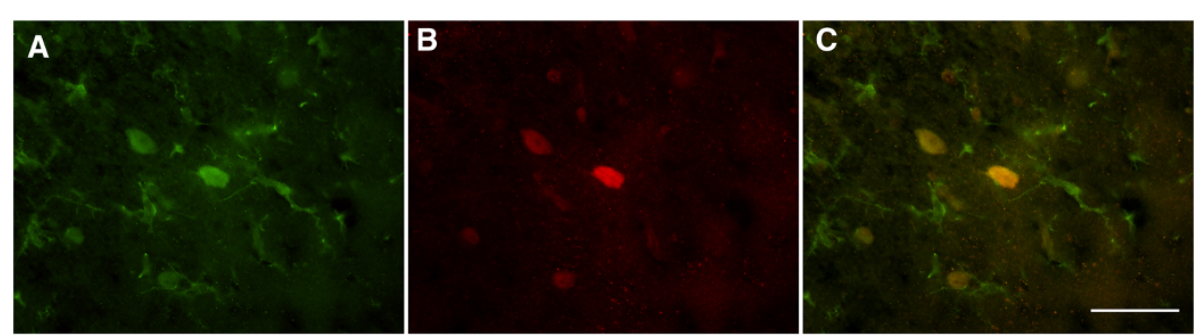

Figure 6 Macrophage/microglial marker, lba-1, and inducible nitric oxide synthase (iNOS) immunofluorescence in the remaining cortical area adjacent to the contusion. Image shows (A) Iba-1 positive cells (green), (B) iNOS positive cells (red), and (C) merged image showing Iba-1 co-localized with iNOS positive cells with a retracted, amoeboid morphology (yellow). 
$\mathrm{CCI}$, confirms the importance of the $\mathrm{CB}_{2}$ pathway in controlling TNF- $\alpha$ expression after TBI. The lack of changes in TNF message transcription with $\mathrm{CB}_{2} \mathrm{R}$ stimulation in this study may be secondary to the post-CCI time point examined. Treatment with a $\mathrm{CB}_{2} \mathrm{R}$ agonist reduced TNF$\alpha$ mRNA at 15 hours after middle cerebral artery occlusion [24]. Fluctuations in TNF- $\alpha$ protein levels have been reported hours to days after CCI injury [41-43]. Cyclical changes in cytokine genes including TNF- $\alpha$ have also been shown after CCI injury in mice [6]. TNF- $\alpha$ mRNA fluctuates over time after injury, in which the levels, albeit increased compared to controls, were at the lowest level at the 1 day time point.

It is important to note that the TNF- $\alpha$ protein levels were reduced by $C_{2} R$ agonist treatment. This suggests additional post-transcriptional or post-translational mechanisms may be involved in attenuating the expression of TNF- $\alpha$ protein. Post-transcriptional modification of RNA ultimately determines expression levels by modulating mRNA stability, transport, and translation efficiency. Several key post-transcriptional regulatory elements include RNA-binding proteins, kinases and phosphatases, degradation enzymes, Au-Rich elements (AREs) and microRNA (miRNA). RNA-binding proteins can silence (or facilitate) the translation of TNF mRNA. For example, RNA-binding proteins, T-cell intracellular Ag (TIA-1) and TIA-1-related protein (TIAR), both silence TNF mRNA [44]; kinases and phosphatases change the binding efficiency of RNA-binding proteins and AREs sites. CNS injury alters the mitogen-activated protein kinase (MAPK) pathway enhancing mRNA stability and the efficacy of inflammatory cytokine generation. Interestingly, a $\mathrm{CB}_{2} \mathrm{R}$ agonist was shown to reduce spinal MAPKs (p38 and p-ERK-1/2) through increased expression of mitogenactivated protein kinase phosphatases (MKP-1 and MKP-3) in primary microglial cells [45] and may explain the reduction in TNF- $\alpha$ protein expression in this study. Additionally, post-translational processes that interfere with the release of soluble TNF- $\alpha$ from its membrane-anchored pre-cursor or promote degradation of the protein may be involved.

Circulating leukocytes infiltrate the brain after cortical injury, reaching maximal accumulation 2 to 3 days after injury $[19,23,46,47]$, which coincides with increases in barrier permeability [23]. ICAM-integrin interactions, in particular, are important for leukocyte adhesion and transendothelial migration to the injured brain. ICAM-1 (CD54) is a cell surface ligand that binds the integrins lymphocyte function-associated antigen-1 (LFA-1, CD11a/ CD18) and macrophage adhesion molecule (Mac-1, CD $11 \mathrm{~b} / \mathrm{CD}$ 18) [7]. After TBI, increased expression of endothelial ICAM-1 helps to precisely guide the migration of leukocytes to the site of injury $[43,48,49]$. Increased expression of ICAM-1 is tightly coupled with changes in macrophage/microglia activation after CCI injury [49]. Past and present findings by our laboratory support the notion that stimulation of the $\mathrm{CB}_{2} \mathrm{R}$ attenuates the inflammatory vascular response to injury. ICAM mRNA levels showed a peak at the 1-day time point that was influenced by the $\mathrm{CB}_{2} \mathrm{R}$ deletion but not synthetic blockade. Results indicate a more pronounced effect on the immune-vascular injury response by genetically modifying the endogenous $\mathrm{CB}$ receptor system. The process of immune cell infiltration into the damaged parenchyma also enhances the permeability of the BBB. At the site of injury, microglia and accumulating immune cells release pro-inflammatory mediators and free radicals, both of which are known to disrupt the neurovascular unit, compromise the integrity of the BBB, and contribute to excitotoxicity and cell toxicity $[8,50,51]$. Disruption of the BBB is especially relevant to TBI as it is a proposed secondary injury mechanism creating a cytotoxic environment for neurons $[52,53]$.

Stimulation of the $\mathrm{CB}_{2} \mathrm{R}$ suppresses activation, chemotaxis, and migration of peripheral macrophages, monocytes, and $\mathrm{T}$ cells, as well as microglial-like cells [15,16,54-58]. These observations suggest that a number of cell types associated with $\mathrm{CNS}$ inflammation express the $\mathrm{CB}_{2} \mathrm{R}$. Insults to the CNS and pro-inflammatory conditions have been found to result in significant upregulation of $\mathrm{CB}_{2} \mathrm{R}$ mRNA expression [13]. $\mathrm{CB}_{2} \mathrm{R}$ mRNA expression is increased 10 -fold by activation of microglia and peripheral macrophages in culture [59]. While there is general agreement that circulating immune cells and microglia express the $\mathrm{CB}_{2} \mathrm{R}$, a controversy exists over the expression of the $\mathrm{CB}_{2} \mathrm{R}$ on other $\mathrm{CNS}$ cell types [14,59-62]. Evidently, this is due to differences in the antibodies used for immunohistochemistry between groups.

Distinctions in the role of infiltrating macrophages and resident microglia in brain injury continues to be a challenge as these cells are both of a monocyte lineage and express many of the same cell-surface markers. Adding to the complexity, is the growing evidence that macrophages and microglia are capable of expressing both pro-inflammatory (M1) and anti-inflammatory (M2) phenotypes $[11,12,30]$. In addition to pro-inflammatory cytokines and adhesion molecules, iNOS is another marker expressed by a M1 cell phenotype and is useful to study these phenotype differences and injury mechanisms. $C_{2} R$ stimulation significantly reduced iNOS mRNA, while genetic deletion substantially exacerbated iNOS expression. Moreover, qualitative analysis of the remaining cortical tissue surrounding the injury showed iNOS expression to be predominantly from a macrophage/microglia cellular source. In a model of TBI, results suggest that the protection offered by a microglial inhibitor, minocycline, may be through cannabinoid receptors as well [63]. Results suggest that selective modulation of the $\mathrm{CB}_{2} \mathrm{R}$ transforms the inflammatory phenotype of the infiltrating and/or immune cells after injury. 


\section{Conclusion}

Modification of the inflammatory vascular responses to TBI through $\mathrm{CB}_{2} \mathrm{R}$ stimulation, as well as receptor blockade and deletion demonstrate the importance of this receptor in recovery from TBI. The $C_{2} R$ is an endogenous regulator of the inflammatory response to $\mathrm{TBI}$, working at the interface between the brain and microvasculature. Macrophage/microglial modulation using $\mathrm{CB}_{2} \mathrm{R}$ agonists has a significant contribution to its protective capabilities $[18,24,25]$. Interventions that limit prolonged microglial activation and neuroinflammation as occurs after TBI, or facilitate a reparative microglial phenotype are proposed to counteract the development of cognitive and affective disorders [30]. Our results further support that $\mathrm{CB}_{2} \mathrm{R}$-dependent pathways regulate the bridge between immune and vascular function following TBI. The development of pharmacological agents to treat TBI may rest in furthering our understanding of the complex immune, vascular, and nervous system interactions that are induced at the time of injury.

\section{Abbreviations}

TBl: traumatic brain injury; CCl: controlled cortical impact; $C_{2}$ R: cannabinoid receptor type-2; TNF-a: tumor necrosis factor-alpha; ICAM-1: intracellular adhesion molecule-1; iNOS: inducible nitric oxide synthase; BBB: blood-brain-barrier; KO: knockout; ELISA: enzyme-linked immunosorbent assay.

\section{Competing interests}

The authors declare that they have no competing interests.

\section{Authors' contributions}

Dr. MBE is the lead principal investigator and Dr. DCH is the collaborating investigator on this project. Dr. RFT gifted the 0-1966 and made substantial editorial contributions. Dr. JIJ provided translational expertise to the project and made significant editorial contributions. Dr. PSA, contributed surgical contributions, as well as provided substantial editorial input. All authors read and approved the final manuscript.

\section{Acknowledgments}

Research support by DOD Award W81XWH-12-1-0326 to Dr. Elliott. We would also like to thank Rhonda Kean (Dr. Hooper's laboratory) for help with RT-PCR and members from Dr. Elliott's laboratory including Brittany Diautolo, Ashley Tyburski, and Christine Macolino for making RT-PCR, immunohistochemistry, and surgical contributions.

\section{Author details}

${ }^{1}$ Department of Neurological Surgery, Thomas Jefferson University Hospital, 1020 Locust Street, Thomas Jefferson University, Philadelphia, PA 19107, USA. 2Department of Cancer Biology, Thomas Jefferson University Hospital, 1020 Locust Street, Thomas Jefferson University, Philadelphia, PA 19107, USA. ${ }^{3}$ Department of Physiology, Temple University School of Medicine, $3500 \mathrm{~N}$ Broad St, Philadelphia, PA 19140, USA.

Received: 23 July 2014 Accepted: 31 October 2014

Published online: 22 November 2014

\section{References}

1. Zaloshnja E, Miller T, Langlois JA, Selassie AW: Prevalence of long-term disability from traumatic brain injury in the civilian population of the United States, 2005. J Head Trauma Rehabil 2008, 23:394-400.

2. Langlois JA, Rutland-Brown W, Wald MM: The epidemiology and impact of traumatic brain injury: a brief overview. J Head Trauma Rehabil 2006, 21:375-378.

3. Erickson MA, Hartvigson PE, Morofuji Y, Owen JB, Butterfield DA, Banks WA: Lipopolysaccharide impairs amyloid beta efflux from brain: altered vascular sequestration, cerebrospinal fluid reabsorption, peripheral clearance and transporter function at the blood-brain barrier. J Neuroinflammation 2012, 9:150.

4. Tomkins O, Feintuch A, Benifla M, Cohen A, Friedman A, Shelef I: Blood-brain barrier breakdown following traumatic brain injury: a possible role in posttraumatic epilepsy. Cardiovasc Psychiatry Neurol 2011, $2011: 765923$.

5. Lenzlinger PM, Morganti-Kossmann MC, Laurer HL, Mclntosh TK: The duality of the inflammatory response to traumatic brain injury. Mol Neurobiol 2001, 24:169-181.

6. Lagraoui M, Latoche JR, Cartwright NG, Sukumar G, Dalgard CL, Schaefer BC: Controlled cortical impact and craniotomy induce strikingly similar profiles of inflammatory gene expression, but with distinct kinetics. Front Neurol 2012, 3:155

7. Dietrich JB: The adhesion molecule ICAM-1 and its regulation in relation with the blood-brain barrier. J Neuroimmunol 2002, 128:58-68.

8. Phares TW, Fabis MJ, Brimer CM, Kean RB, Hooper DC: A peroxynitritedependent pathway is responsible for blood-brain barrier permeability changes during a central nervous system inflammatory response: TNF-alpha is neither necessary nor sufficient. J Immunol 2007, 178:7334-7343.

9. Walker PA, Shah SK, Jimenez F, Gerber MH, Xue H, Cutrone R, Hamilton JA, Mays RW, Deans R, Pati S, Dash PK, Cox CS Jr: Intravenous multipotent adult progenitor cell therapy for traumatic brain injury: preserving the blood brain barrier via an interaction with splenocytes. Exp Neurol 2010, 225:341-352.

10. Hailer NP: Immunosuppression after traumatic or ischemic CNS damage: it is neuroprotective and illuminates the role of microglial cells. Prog Neurobiol 2008, 84:211-233.

11. Cherry JD, Olschowka JA, O'Banion MK: Neuroinflammation and M2 microglia: the good, the bad, and the inflamed. J Neuroinflammation 2014, 11:98.

12. Turtzo LC, Lescher J, Janes L, Dean DD, Budde MD, Frank JA: Macrophagic and microglial responses after focal traumatic brain injury in the female rat. J Neuroinflammation 2014, 11:82.

13. Cabral GA, Griffin-Thomas L: Emerging role of the cannabinoid receptor CB2 in immune regulation: therapeutic prospects for neuroinflammation. Expert Rev Mol Med 2009, 11:e3.

14. Cabral GA, Raborn ES, Griffin L, Dennis J, Marciano-Cabral F: CB2 receptors in the brain: role in central immune function. Br J Pharmacol 2008, 153:240-251.

15. Buckley NE, McCoy KL, Mezey E, Bonner T, Zimmer A, Felder CC, Glass M, Zimmer A: Immunomodulation by cannabinoids is absent in mice deficient for the cannabinoid CB(2) receptor. Eur J Pharmacol 2000, 396:141-149.

16. Fraga D, Raborn ES, Ferreira GA, Cabral GA: Cannabinoids inhibit migration of microglial-like cells to the HIV protein Tat. J Neuroimmune Pharmacol 2011, 6:566-577.

17. Munro S, Thomas KL, Abu-Shaar M: Molecular characterization of a peripheral receptor for cannabinoids. Nature 1993, 365:61-65.

18. Palazuelos J, Aguado T, Pazos MR, Julien B, Carrasco C, Resel E, Sagredo O, Benito C, Romero J, Azcoitia I, Fernández-Ruiz J, Guzmán M, Galve-Roperh I: Microglial CB2 cannabinoid receptors are neuroprotective in Huntington's disease excitotoxicity. Brain 2009, 132:3152-3164.

19. Elliott MB, Tuma RF, Amenta PS, Barbe MF, Jallo Jl: Acute effects of a selective cannabinoid-2 receptor agonist on neuroinflammation in a model of traumatic brain injury. J Neurotrauma 2011, 28:973-981.

20. Zhang M, Adler MW, Abood ME, Ganea D, Jallo J, Tuma RF: CB2 receptor activation attenuates microcirculatory dysfunction during cerebral ischemic/reperfusion injury. Microvasc Res 2009, 78:86-94.

21. Zhang M, Martin BR, Adler MW, Razdan RK, Jallo Jl, Tuma RF: Cannabinoid $\mathrm{CB}(2)$ receptor activation decreases cerebral infarction in a mouse focal ischemia/reperfusion model. J Cereb Blood Flow Metab 2007, 27:1387-1396.

22. Adhikary S, Li H, Heller J, Skarica M, Zhang M, Ganea D, Tuma RF: Modulation of inflammatory responses by a cannabinoid-2-selective agonist after spinal cord injury. J Neurotrauma 2011, 28:2417-2427.

23. Amenta PS, Jallo Jl, Tuma RF, Elliott MB: A cannabinoid type 2 receptor agonist attenuates blood-brain barrier damage and neurodegeneration in a murine model of traumatic brain injury. J Neurosci Res 2012, 90:2293-22305.

24. Zarruk JG, Fernandez-Lopez D, Garcia-Yebenes I, Garcia-Gutierrez MS, Vivancos J, Nombela F, Torres M, Burguete MC, Manzanares J, Lizasoain I, Moro MA: Cannabinoid type 2 receptor activation downregulates stroke-induced classic and alternative brain macrophage/microglial activation concomitant to neuroprotection. Stroke 2012, 43:211-219.

25. Price DA, Martinez AA, Seillier A, Koek W, Acosta Y, Fernandez E, Strong R, Lutz B, Marsicano G, Roberts JL, Giuffrida A: WIN55,212-2, a cannabinoid 
receptor agonist, protects against nigrostriatal cell loss in the 1-methyl4-phenyl-1,2,3,6-tetrahydropyridine mouse model of Parkinson's disease. Eur J Neurosci 2009, 29:2177-2186.

26. Cabral GA, Marciano-Cabral F: Cannabinoid receptors in microglia of the central nervous system: immune functional relevance. J Leukoc Biol 2005, 78:1192-1197.

27. Romero-Sandoval EA, Horvath R, Landry RP, DeLeo JA: Cannabinoid receptor type 2 activation induces a microglial anti-inflammatory phenotype and reduces migration via MKP induction and ERK dephosphorylation. Mol Pain 2009, 5:25.

28. Gentleman SM, Leclercq PD, Moyes L, Graham DI, Smith C, Griffin WS, Nicoll JA: Long-term intracerebral inflammatory response after traumatic brain injury. Forensic Sci Int 2004, 146:97-104.

29. Loane DJ, Byrnes KR: Role of microglia in neurotrauma. Neurotherapeutics 2010, 7:366-377

30. Norden DM, Godbout JP: Review: microglia of the aged brain: primed to be activated and resistant to regulation. Neuropathol Appl Neurobiol 2013, 39:19-34.

31. Lighthall JW: Controlled cortical impact: a new experimental brain injury model. J Neurotrauma 1988, 5:1-15.

32. Elliott MB, Oshinsky ML, Amenta PS, Awe OO, Jallo Jl: Nociceptive neuropeptide increases and periorbital allodynia in a model of traumatic brain injury. Headache 2012, 52:966-984.

33. Wiley JL, Beletskaya ID, Ng EW, Dai Z, Crocker PJ, Mahadevan A, Razdan RK, Martin BR: Resorcinol derivatives: a novel template for the development of cannabinoid $\mathrm{CB}(1) / \mathrm{CB}(2)$ and $\mathrm{CB}(2)$-selective agonists. J Pharmacol Exp Ther 2002, 301:679-689.

34. Zhang M, Martin BR, Adler MW, Razdan RJ, Kong W, Ganea D, Tuma RF: Modulation of cannabinoid receptor activation as a neuroprotective strategy for EAE and stroke. J Neuroimmune Pharmacol 2009, 4:249-259.

35. Phares TW, Kean RB, Mikheeva T, Hooper DC: Regional differences in blood-brain barrier permeability changes and inflammation in the apathogenic clearance of virus from the central nervous system. $\mathrm{J}$ Immunol 2006, 176:7666-7675.

36. Pertwee RG: Receptors and channels targeted by synthetic cannabinoid receptor agonists and antagonists. Curr Med Chem 2010, 17:1360-1381.

37. Fishbein-Kaminietsky M, Gafni M, Sarne $Y$ : Ultralow doses of cannabinoid drugs protect the mouse brain from inflammation-induced cognitive damage. J Neurosci Res 2014, 92:1669-1677.

38. Ashton JC, Glass M: The cannabinoid CB2 receptor as a target for inflammation-dependent neurodegeneration. Curr Neuropharmacol 2007, 5:73-80.

39. Ramirez SH, Hasko J, Skuba A, Fan S, Dykstra H, McCormick R, Reichenbach N, Krizbai I, Mahadevan A, Zhang M, Tuma R, Son YJ, Persidsky Y: Activation of cannabinoid receptor 2 attenuates leukocyte-endothelial cell interactions and blood-brain barrier dysfunction under inflammatory conditions. J Neurosci 2012, 32:4004-4016.

40. Reglero-Real N, Marcos-Ramiro B, Millan J: Endothelial membrane reorganization during leukocyte extravasation. Cell Mol Life Sci 2012, 69:3079-3099.

41. Harting MT, Jimenez F, Adams SD, Mercer DW, Cox CS Jr: Acute, regional inflammatory response after traumatic brain injury: implications for cellular therapy. Surgery 2008, 144:803-813.

42. Shein S, Shellington DK, Exo J, Jackson TC, Wisniewski SR, Jackson E, Vagni VA, Bayir H, Clark R, Dixon CE, Janesko-Feldman KL, Kochanek PM: Hemorrhagic shock shifts the serum cytokine profile from pro-to anti-inflammatory after experimental traumatic brain injury in mice. J Neurotrauma 2014, 31:1386-1395.

43. Li GZ, Zhang Y, Zhao JB, Wu GJ, Su XF, Hang CH: Expression of myeloid differentiation primary response protein 88 (Myd88) in the cerebral cortex after experimental traumatic brain injury in rats. Brain Res 2011 1396:96-104.

44. Giambelluca MS, Rollet-Labelle E, Bertheau-Mailhot G, Laflamme C, Pouliot M: Post-transcriptional regulation of tumor necrosis factor alpha biosynthesis: relevance to pathophysiology of rheumatoid arthritis. OA Inflammation 2013, 1:3.

45. Landry RP, Martinez E, Deleo JA, Romero-Sandoval EA: Spinal cannabinoid receptor type 2 agonist reduces mechanical allodynia and induces mitogen-activated protein kinase phosphatases in a rat model of neuropathic pain. J Pain 2012, 13:836-848.
46. Bayir H, Kagan VE, Borisenko GG, Tyurina YY, Janesko KL, Vagni VA, Billiar TR, Williams DL, Kochanek PM: Enhanced oxidative stress in iNOS-deficient mice after traumatic brain injury: support for a neuroprotective role of iNOS. J Cereb Blood Flow Metab 2005, 25:673-684.

47. Foley LM, Hitchens TK, Ho C, Janesko-Feldman KL, Melick JA, Bayir H, Kochanek PM: Magnetic resonance imaging assessment of macrophage accumulation in mouse brain after experimental traumatic brain injury. J Neurotrauma 2009, 26:1509-1519.

48. Hang CH, Shi JX, Li JS, Wu W, Yin HX: Concomitant upregulation of nuclear factor-kB activity, proinflammatory cytokines and ICAM-1 in the injured brain after cortical contusion trauma in a rat model. Neurol India 2005, 53:312-317.

49. Khan M, Im YB, Shunmugavel A, Gilg AG, Dhindsa RK, Singh AK, Singh I: Administration of S-nitrosoglutathione after traumatic brain injury protects the neurovascular unit and reduces secondary injury in a rat model of controlled cortical impact. J Neuroinflammation 2009, 6:32.

50. Fabis MJ, Phares TW, Kean RB, Koprowski H, Hooper DC: Blood-brain barrier changes and cell invasion differ between therapeutic immune clearance of neurotrophic virus and CNS autoimmunity. Proc Natl Acad Sci U S A 2008, 105:15511-15516.

51. Nag S: Pathophysiology of blood-brain barrier breakdown. Methods Mol Med 2003, 89:97-119.

52. Neuwelt EA, Bauer B, Fahlke C, Fricker G, ladecola C, Janigro D, Leybaert L, Molnar Z, O'Donnell ME, Povlishock JT, Saunders NR, Sharp F, Stanimirovic D, Watts RJ, Drewes LR: Engaging neuroscience to advance translational research in brain barrier biology. Nat Rev Neurosci 2011, 12:169-182.

53. Persidsky Y, Ramirez SH, Haorah J, Kanmogne GD: Blood-brain barrier: structural components and function under physiologic and pathologic conditions. J Neuroimmune Pharmacol 2006, 1:223-236.

54. Sacerdote $P$, Massi $P$, Panerai $A E$, Parolaro $D:$ In vivo and in vitro treatment with the synthetic cannabinoid CP55, 940 decreases the in vitro migration of macrophages in the rat: involvement of both $C B 1$ and $C B 2$ receptors. J Neuroimmunol 2000, 109:155-163.

55. Walter L, Stella N: Cannabinoids and neuroinflammation. Br J Pharmacol 2004, 141:775-785.

56. Montecucco F, Burger F, Mach F, Steffens S: CB2 cannabinoid receptor agonist JWH-015 modulates human monocyte migration through defined intracellular signaling pathways. Am J Physiol Heart Circ Physiol 2008, 294:H1145-H1155.

57. Correa F, Mestre L, Docagne F, Guaza C: Activation of cannabinoid $C B 2$ receptor negatively regulates $\mathrm{IL}-12 \mathrm{p} 40$ production in murine macrophages: role of IL-10 and ERK1/2 kinase signaling. $\mathrm{Br} J$ Pharmacol 2005, 145:441-448.

58. Lombard C, Nagarkatti M, Nagarkatti P: CB2 cannabinoid receptor agonist, JWH-015, triggers apoptosis in immune cells: potential role for CB2-selective ligands as immunosuppressive agents. Clin Immunol 2007, 122:259-270.

59. Maresz K, Carrier EJ, Ponomarev ED, Hillard CJ, Dittel BN: Modulation of the cannabinoid CB2 receptor in microglial cells in response to inflammatory stimuli. J Neurochem 2005, 95:437-445.

60. Ashton JC: Knockout controls and the specificity of cannabinoid CB2 receptor antibodies. Br J Pharmacol 2011, 163:1113.

61. Ashton JC: The use of knockout mice to test the specificity of antibodies for cannabinoid receptors. Hippocampus 2012, 22:643-644.

62. Atwood BK, Mackie K: CB2: a cannabinoid receptor with an identity crisis. Br J Pharmacol 2010, 160:467-479.

63. Lopez-Rodriguez AB, Siopi E, Finn DP, Marchand-Leroux C, Garcia-Segura LM, Jafarian-Tehrani M, Viveros MP: CB1 and CB2 cannabinoid receptor antagonists prevent minocycline-induced neuroprotection following traumatic brain injury in mice. Cereb Cortex 2013. doi:10.1093/cercor/ bht202

\section{doi:10.1186/s12974-014-0191-6}

Cite this article as: Amenta et al:: Cannabinoid receptor type-2 stimulation, blockade, and deletion alter the vascular inflammatory responses to traumatic brain injury. Journal of Neuroinflammation 2014 11:191. 